\title{
Optimization design of plate-type radiator
}

\author{
H. L. Shi, Y. Liu, Y. Z. Shao, Y. A. Jin \\ State Key Laboratory of Automotive Simulation and Control \\ Jilin University \\ Changchun, China \\ College of Automotive Engineering \\ Jilin University \\ Changchun, China
}

\begin{abstract}
Recently, most of research at home and abroad focuses on the analysis of transformer thermal problems, but there is little research about optimum design of plate-type radiator. From the perspective of heat transfer and fluid mechanics, theoretical analysis and simulation calculation were used to transform the plate-type radiator structure. It can be seen from the results that the oil duct optimum angle is $13^{\circ} \sim 20^{\circ}$, at the same time the big oil duct is divided into three small oil ducts; the heat transfer efficiency is higher. When the side oil duct is designed into wide one and the middle duct is designed into narrow oil duct, it will obtain well heat transfer effect.
\end{abstract}

Keywords-plate-type radiator; single plate; optimum design

\section{INTRODUCTION}

With the rapid development of science and technology, the level of national economy, the need of electrical energy is increasing sharply, the electric power system moves in the direction towards large capacity, large electricity grid, UHV direction gradually. For the existence of resistance and magneto resistance, the running of the transformer will have tremendous heat loss from iron core, coil and steel structure, the transformer temperature rises quickly. With the transformer capacity increased, transformer overheating problems have become increasingly prominent [1]. The transformer temperature is too high to increase the transmission damage, to decline the insulation resistance of transformer insulation material, to accelerate the ageing of insulating material, which causes partial discharged ,the output capacity greatly lower than the rated capacity, and reduces the efficiency of the transformer, shorten the service life of transformer[2]. Plate-type radiator is the main form for transformer cooling, which is constrained by around space. How to improve the heat dissipation capacity and accelerate the transformer cooling speed and efficiency to prolong the life of the transformer is an urgent problem in engineering [3].

\section{THE OPTIMIZATION CALCULATION}

This paper describes the structural optimization for single plate of radiator and studies the effect on transformer oil cooling heat transfer; it will provide guidance for the practical engineering application. The type of radiator in the paper is PC2500-26/520.

Calculation parameters: (1) inlet temperature of air is $30^{\circ} \mathrm{C}$, entrance velocity of air is $0.1 \mathrm{~m} / \mathrm{s}$, (2) inlet temperature of transformer oil is $80^{\circ} \mathrm{C}$, entrance velocity of transformer oil is $0.01 \mathrm{~m} / \mathrm{s}$, entrance density of transformer oil is $871 \mathrm{~kg} / \mathrm{m}^{3}$, kinetic viscosity of transformer oil is $11 \times 10^{-6} \mathrm{~m}^{2} / \mathrm{s}$. The wall boundary condition is convection and radiation.

\section{A. Structure Transformation}

The structure of single plate is optimized; the upper oil duct flat structure is changed into dropped-shoulder structure, which is shown in fig 1 . The plate's flat oil duct is peeled a certain angle, the excess metal is not cut off, which makes the upper duct is winded gradually, the plate pressure distribution in consistency, so that the transformer oil in single plate heat transfer fully. In the simulation, the type of oil duct is big oil duct, (the size of which is $45 \mathrm{~mm} \times 9 \mathrm{~mm}$ ), the height is $2600 \mathrm{~mm}$.
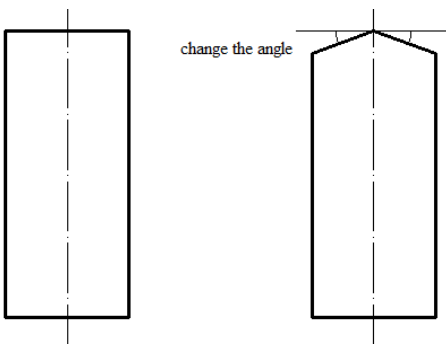

(a) original structure(b) optimized structure.

FIGURE I. THE DIAGRAM OF STRUCTURAL TRANSFORMATION

The transformed structure single plate is shown in fig 2, the single plate in transformer cooling oil duct is divided into 7 small ducts, at the centre of middle oil duct, arranged symmetrically on both sides. Because of the symmetrical

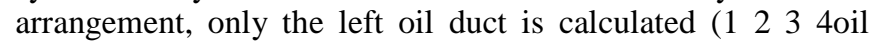
duct).

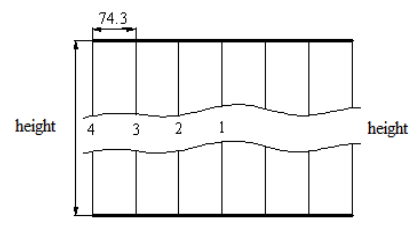

(a) original structure FIGURE II. THE STRUCTURE OF SINGLE-PLATE.
When the angle of single plat is $0^{\circ}, 10^{\circ}, 20^{\circ}$ and $30^{\circ}$, the heat transfer effect of transformation is analyzed. With the plate oil duct dropped-shoulder angle increasing, heat transfer efficiency first increases and then decreases. When $0^{\circ}, 10^{\circ}$, $20^{\circ}$ and $30^{\circ}$, single plate heat efficiency are $1.00,1.18,1.28$, 1.11 respectively, the calculation result is shown in fig 3 . With 
the increasing of the angle the heat transfer is enhanced, once the angle exceeds $20^{\circ}$, the effect will decrease gradually.

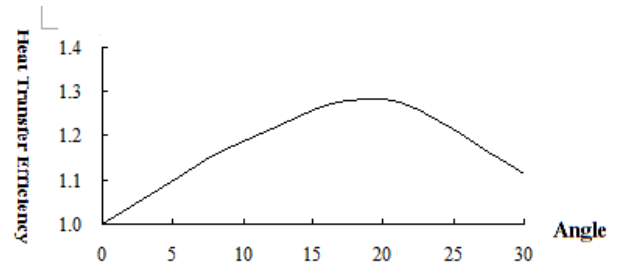

FIGURE III. THE VARIATION OF HEAT TRANSFER EFFICIENCY AT CHANGED ANGLE.

The temperature field is shown in fig 4 , it is found that the bigger angle, the lower temperature. While the angle exceeds $20^{\circ}$, the effect will decline.

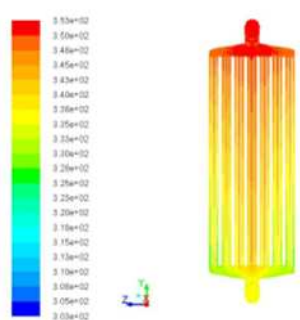

(a) $0^{\circ}$

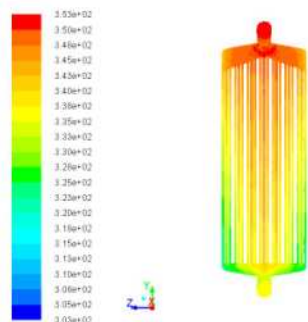

(c) $20^{\circ}$

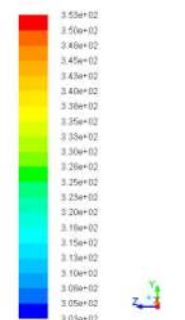

(b) $10^{\circ}$

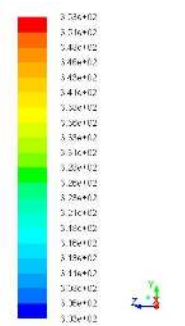

(d) $30^{\circ}$
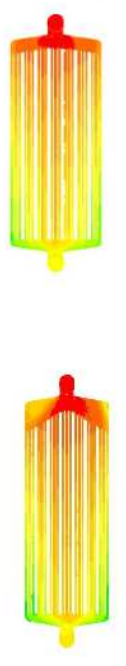

FIGURE IV. TEMPERATURE FIELD.

\section{B. Structure of Oil Duct}

In order to research the effect of the structural change of single plate's oil duct on the heat transfer of transformer cooling oil, analyzing two kinds of single plate is analyzed (the structure shown in fig 5). In the simulation, assuming the height is $2600 \mathrm{~mm}$, the size of big oil duct is $45 \mathrm{~mm} \times 9 \mathrm{~mm}$. The other is small oil duct. Each of the big oil ducts is divided into 3 small ducts, the size of the middle one is $23 \mathrm{~mm} \times 9 \mathrm{mmis}$ wide, the size of two small oil duct on both sides is $18 \mathrm{~mm} \times 9 \mathrm{~mm}$. The dropped-shoulder angle is $20 \mathrm{o}$.

According to the analysis results of different types of oil duct, small oil duct and big oil duct heat Efficiency is 1.00 and 0.70 respectively.

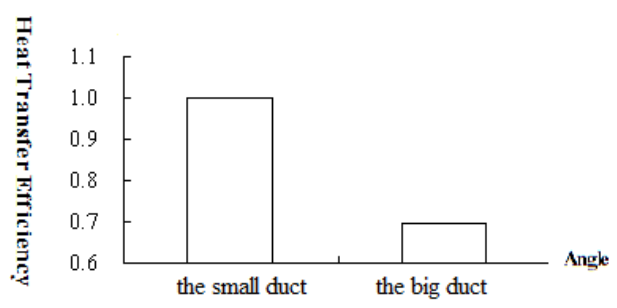

FIGURE V. THE VARIATION OF HEAT TRANSFER EFFICIENCY AT CHANGED DUCT.

As shown in fig 5, the heat transfer efficiency of the small duct is 1.0 , the big one is 0.7 . The small oil duct has a better effect on heat transfer, it can be proved by the temperature field in fig 6. It is found that the temperature of the small oil duct is low; the transformer cooling oil gets a better heat transfer ability.

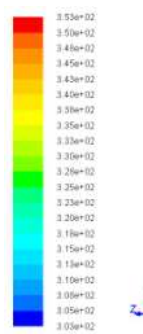

(a)the small duct

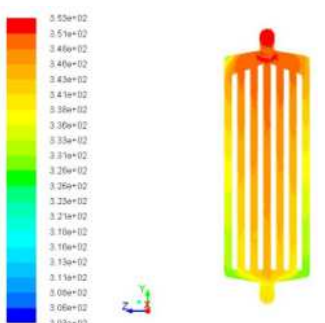

(b)the big duct
FIGURE VI.TEMPERATURE FIELD.

\section{Duct Distribution}

The oil duct distribution form is analyzed, there are three types distribution forms, which are big to small, well-distributed, small to big. The transformed angle of them is $20^{\circ}$.

The big oil duct distribution mode: (1)from the middle to both sides-oil duct width are $50 \mathrm{~mm}, 46 \mathrm{~mm}, 43 \mathrm{~mm}, 40 \mathrm{~mm}$ (short for big to small), (2)oil duct width for the uniform distribution of $45 \mathrm{~mm}$, (3) from the middle to both sides are $40 \mathrm{~mm}, 43 \mathrm{~mm}, 46 \mathrm{~mm}, 50 \mathrm{~mm}$ (short for small to big), in fig 7 , the heat transfer efficiency is $0.86,1.00$ and 1.03 respectively. It is found that the oil duct distribution in the form of middle oil narrow and both sides oil duct width is better.

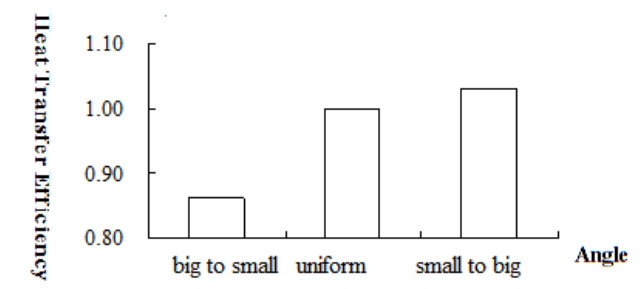

$$
\begin{aligned}
& \text { FIGURE VII. THE VARIATION OF HEAT TRANSFER } \\
& \text { EFFICIENCY. }
\end{aligned}
$$

The result can be acquired by the temperature field, which is shown in fig 8 . 


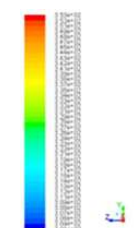

(a) big to smal

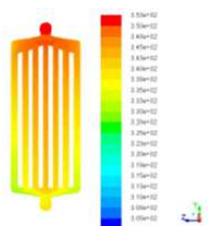

(b) uniform

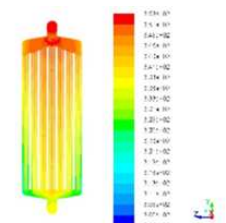

(c) small to big

FIGURE VIII. TEMPERATURE FIELD

The flow resistance of the middle duct is small, the other sides are big, and it makes more flow in the middle duct and uneven distribution of the flow rate. The design of wide middle duct and narrow other sides avoid uneven distribution, make the flow distribution uniform and the situation of heat transfer is improved.

\section{CONCLUSIONS}

According to the three sets of experiments and simulation results, the following conclusions can be obtained:

With the growth of upper oil duct dropped-shoulder, the heat transfer efficiency first increases and then decreases. When the dropped-shoulder exceeds to $20^{\circ}$, the efficiency declines sharply, the optimum angle of the upper oil duct is $13^{\circ} \sim 20^{\circ}$, dropped-shoulder angle is less than $20^{\circ}$.

The big oil duct is divided into three small oil duct, the calculation results show small oil duct heat transfer efficiency is higher than that of big oil duct.

The form of wide side and narrow middle duct will avoid the uneven distribution of flow and improve the ability of heat transfer.

\section{REFERENCES}

[1] Yafeng Liang, Study Temperature Distribution Characteristics and Hotspot Location on Transformer Winding Temperature, pp. 1, 2010.

[2] Changbin Zhang, Research on a New Type of Cooling System of Power Transformer. Transformer, 42(8), pp. 36-37,2005.

[3] Xia Zhang, Xiuchun Wang \& Xiaoxia Guo, CFD Simulation and Infrared Test Research of Influence of Internal of Structure of Panel Type Radiator to Heat Elimination. Transformer, 48(3), pp.62-66, 2011. 